UDK: 528.44

DOI: https://doi.org/10.24867/03KO06Markovic

\title{
FORMIRANJE KOMPLEKSNOG PROSTORNOG MODELA PRIMENOM TEHNIKE SKENIRANJA GEORADAROM
}

\section{COMPLEX UNDERGROUND STRUCTURE MODEL CREATION BY USING GROUND PENETRATING RADAR TEHNOLOGY}

\author{
Miljana Marković, Fakultet tehničkih nauka, Novi Sad
}

\section{Oblast - GEODEZIJA I GEOMATIKA}

Kratak sadržaj - U radu je ispitana mogućnost primene GPR tehnologije za potrebe formiranja pojedinačnih $i$ kompleksnih $3 D$ modela korišćenjem antena frekvencije $400 \mathrm{MHz}$ i $900 \mathrm{MHz}$. Najveći akcenat je na detektovanju $i$ prostornom položaju toplovodnih cevi u modelu zbog njihovog specifičnog načina izrade. Izvršeno je georeferenciranje kreiranih modela primenom TS $i$ GNSS uređaja, a dobijeni podaci eksportovani su i prikazani u GIS aplikaciji.

Ključne reči: GPR tehnologija, GIS aplikacija

Abstract - This thesis investigates the possibility of applying the GPR technology in order to create individual and complex underground structure models. This is done by using $400 \mathrm{MHz}$ and $900 \mathrm{MHz}$ frequency antennas. The detection and spatial position of heating pipes are emphasized in the model due to their special production process. The models have been georeferenced by means of the TS and GNSS devices. The data acquired have been exported and represented in the GIS application.

Key words: GPR technology, GIS aplication

\section{UVOD}

Detekcija objekata podzemne infrastrukture predstavlja postupak utvrđivanja stvarnog stanja vodova, njihove identifikacije i georeferenciranja.

Glavni cilj jeste otkrivanje položaja podzemnih objekata bez otkopavanja, koristeći odgovarajuće vrste uređaja za detekciju. Georeferenciranjem dobijenih podataka dobijaju se koordinate detektovanih objekata $\mathrm{i}$ njihov precizan položaj u prosotru, čija vizuelizacija je moguća u različitim GIS alatima.

\section{TEHNOLOGIJA DETEKCIJE OBJEKATA PODZEMNE INFRASTRUKTURE}

Georadar je uređaj koji služi za detekciju i tačno utvrđivanje pozicije objekata podzemne infrastrukture. Radi na principu analize reflektovanih elektromagnetnih signala, na osnovu koje se prikupljaju informacije o različitim karakteristikama zemlje i instalacija [1].

Akvizicija jednog reflektovanog signala sa jedinstvene lokacije, bez kretanja antene, naziva se A sken. Niz sukcesivno povezanih skenova u jednom smeru kretanja antene čini 2D radargram čijom kombinacijom 3D model,

\section{NAPOMENA:}

Ovaj rad proistekao je iz master rada čiji mentor je bio dr Aleksandar Ristić. a više 3D modela u jednom sistemu čini kompleksan prostorni, odnosno super 3D model.

\section{FORMIRANJE 3D I SUPER 3D MODELA}

3D modeli pružaju jasniju predstavu objekata podzemne infrastrukture i pogodni su za otkrivanje podzemnih vodova, posebno kada se očekuje velik broj instalacija. Kombinovanjem dva ili više 3D modela, formira se super 3D model.

Pojedinačni 3D modeli u kompleksnom prostornom modelu, mogu biti u različitom prostornom odnosu, da se preklapaju ili pružaju dijagonalno u odnosnu na osnovnu mrežu. Takođe, neophodno je izvršiti njihovo georeferenciranje, tj. koordinatni sistemi modela moraju biti međusobno usklađeni.

Formiranjem super 3D modela i njihovim georeferenciranjem mogu se povezivati udaljeni delovi nekog voda povezani u jedan koordinatni sistem.

\section{TOPLOVOD}

Najveći akcenat u ovom radu je na prostornom položaju i formiranju složenih 3D modela toplovodnih cevi, zbog njihovog specifičnog načina izrade $i$ postavljanja $u$ zemlju.

Postoji jednocevni, dvocevni i trocevni sistem. Karakteristično za toplovodne vodove je postavljanje lira, odnosno temperaturnih kompenzatora, da bi bila izvršena kompenzacija toplotnih dilatacija. Dakle, trasa cevovoda se menja i dobija U, L ili Z obllik.

\section{LOKACIJA}

Lokacija odabrana za prikupljanje podataka potrebnih za formiranje složenog 3D modela nalazi se u Ulici Veljka Petrovića u Novom Sadu. Ovo područje sadrži specifičnu trasu pružanja voda, reprezentativnu za anlazu i predstavljanje super 3D modelom, te je iz tog razloga odabrano za lokaciju snimanja (Slika 1).

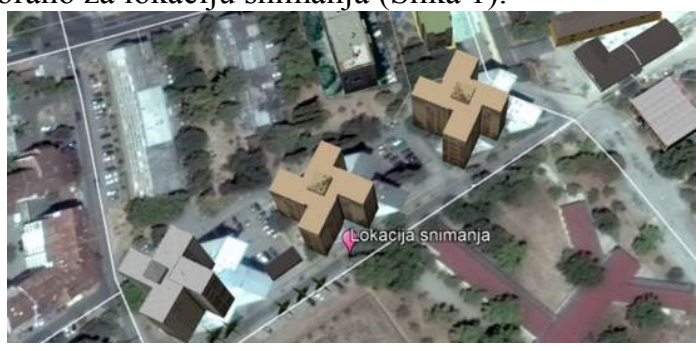

Slika 1: Lokacija od interesa

Kako bi skeniranje bilo što efikasnije izvršeno, proučena je lokacija na osnovu pribavljenih planova i ostalih podataka. Zaključeno je da se na lokaciji nalaze sledeći podzemni vodovi: TO 2x80 ( $\phi$ 125) , V2" ( $\phi$ 60.3) - 
vodovodna cev, E1kV - elektroenergetski vod, kanalizacija K250. Očekivan položaj pomenutih vodova prikazan je na Slici 2.

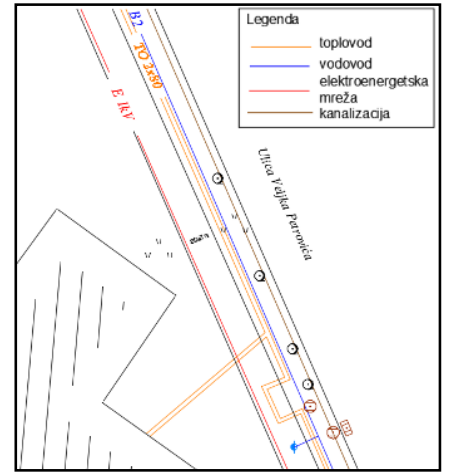

Slika 2: Očekivan položaj vodova

\section{AKVIZICIJA PODATAKA}

Akvizicija podataka podrazumeva skeniranje potpovršinskog sloja georadarom za potrebe formiranja više podzemnih 3D modela. Da bi formiranje 3D modela bilo moguće, neophodno je izvršiti veći broj skeniranja po obe ose koje će formirati 3D modele. Prilikom skeniranja korišćena su dva tipa antena: antena od $400 \mathrm{MHz}$ i antena od 900MHz. U Tabeli 1 date su dimenzije mreža prilikom korišćenja snimanja.

Tabela 1: Dimenzije mreža za formiranje 3D modela

\begin{tabular}{||c|c|c||c|c||}
\hline \hline $\begin{array}{c}\text { Oznaka } \\
\text { mreže }\end{array}$ & $\begin{array}{c}\text { Y osa } \\
{[\mathrm{m}]}\end{array}$ & \multirow{2}{*}{$\begin{array}{c}\text { X osa } \\
{[\mathrm{m}]}\end{array}$} & \multicolumn{2}{|c|}{ Rastojanje između linija skeniranja } \\
\cline { 5 - 5 } & & $400 \mathrm{MHz}$ & $900 \mathrm{MHz}$ \\
\hline \hline 3D - 1 & 5 & 5 & \multirow{2}{*}{$1 \mathrm{~m}$} & $0.5 \mathrm{~m}$ \\
\hline \hline 3D - 2 & 5 & 3 & & \\
\hline \hline 3D - 3 & 4 & 3 & & \\
\hline
\end{tabular}

Na slici 3 prikazane su skice položaja mreža za formiranje 3D modela, gde skica levo predstavlja mreže za korišćenje antene od $400 \mathrm{MHz}$, a skica desno za antenu od 900 $\mathrm{MHz}$.

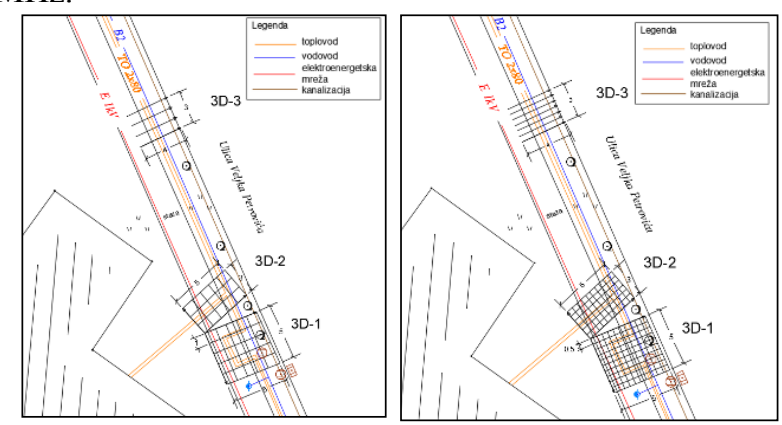

Slika 3: Skica mreža skeniranja za svaku od antena

Nakon prikupljanja podataka georadarom, izvršeno je snimanje koordinata karakterističnih tačaka modela. Snimljene su tačke koje predstavljaju početak i kraj svakog skeniranog radargrama koji pripada mreži za formiranje modela snimanog antenom od $400 \mathrm{MHz}$. Prilikom snimanja korišćen je GPS prijemnik i totalna stanica, a koordinate su dobijene u UTM projekciji. Na osnovu ovih koordinata biće izvršeno georeferenciranje čitavog super 3D modela.

\section{SOFTVERSKA OBRADA PODATAKA}

U softverskom paketu RADAN 6.6.2.7. izvršena je obrada prikupljenih podataka na terenu. Obrada podataka obuhvata odstranjivanje nevažnih informacija iz radargrama, ali i naglašavanje i rad sa informacijama od koristi. Dobijeni radargrami najčešće sadrže smetnje poput šumova, interferencije i dupliranja hiperboličnih refleksija, pa je neophodno pre analize podataka pristupiti obradi snimaka.

\subsection{Georeferenciranje podataka}

Da bi georeferenciranje bilo obavljeno, potrebno je pristupiti bazi podataka $R A D A N$-a. Većina podataka ove baze ne može biti izmenjena direktno u bazi samog softvera, već joj je potrebno pristupiti otvaranjem pojedinačnog *.mdb fajla za svaki radargram [2].

Rezultat je georeferenciran radargram za čiji se svaki sken mogu videti vrednosti njegovih koordinata u UTM projekciji u donjem delu interfejsa programa (Slika 4).

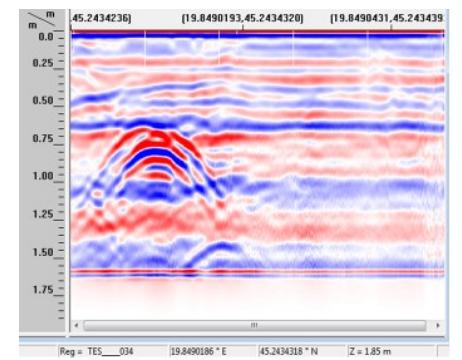

Slika 4 - georeferenciran radargram

\subsection{Formiranje modela}

Da bi bio formiran super 3D model, neophodno je prethodno kreirati više $3 \mathrm{D}$ modela. Za kreiranje 3D modela iskorišćen je $3 D$ QuickDraw modul u RADAN-u, a s obzirom da su korišćene dve antene, formirana su dva složena modela. Za svaki od ta dva super modela, formirano je po tri pojedinačna 3D modela.

Prilikom formiranja modela koriste se georeferencirani radargrami da bi i sam 3D model bio georeferenciran. Iz tog razloga kao početak koordinatnog sistema unosi se koordinata u UTM projekciji i definišu neophodni parametri.

\subsubsection{Problem georeferenciranja 3D modela}

Kako su u prozoru $3 D$ Grid Options unesene UTM vrednosti koordinatnog početka mreže 3D-1, kao i dužine koordinatnih osa po kojima je vršeno skeniranje, ubacivanjem radargrama $i$ pokretanjem formiranja modela, dobijeni model je georeferenciran tako da su na početnu koordinatu dodate vrednosti dužina koordinatnih osa. Te vrednosti predstavljaju koordinate krajnjih tačaka $\mathrm{X}$ i Y ose i na osnovu njih izgenerisane su i koordinate za svaki sken u 3D modelu. Dakle, program nije uzeo u obzir koordinate ubačenih georeferenciranih radargrama, već formirao nove vrednosti na pomenuti način, automatski podrazumevajući da $\mathrm{Y}$ osa uvek stoji vertikalno, a $\mathrm{X}$ osa horizontalno. RADAN 6.6.2.7. korišćen pri obradi ovih podataka nema opciju izmene tako postavljenog koordinatnog sistema, pa je rezultat netačno georeferenciran model, koji u stvari nije pravilno orjentisan.

Zbog nemogućnosti tačnog georeferenciranja 3D modela, njihovo dalje formiranje nastavljeno je u lokalnom koordinatnom sistemu, sa radargramima u koje nisu unesene vrednosti koordinata. 


\subsection{Rad sa 3D modelima}

Prikaz svakog od pojedinačnih modela dobijenih antenom od $400 \mathrm{MHz}$, na dubini (oko 0.60m) koja najbolje prikazuje toplovodne cevi od interesa nalazi se na Slici 5.

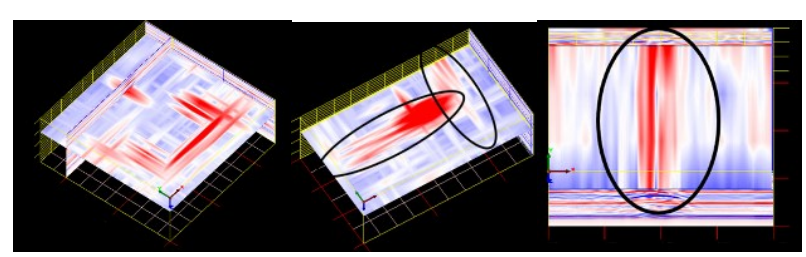

Slika 5 - prikaz pojedinačnih 3D modela (400 MHz)

Isti postupak formiranja 3D modela ponovljen je i za podatke dobijene snimanjem antenom frekvencije 900 MHz (Slika 6).

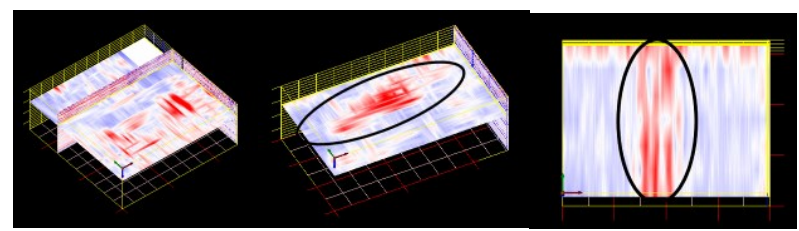

Slika 6 - prikaz pojedinačnih 3D modela $(900 \mathrm{MHz})$

\subsection{Kreiranje i georeferenciranje super 3D modela}

Nakon formiranja pojedinačnih 3D modela, usledelo je kreiranje složenog, odnosno super 3D modela.

Složeni prostorni model prvo je neophodno georeferencirati. S obzriom da su pojedinačni 3D modeli georeferencirani samo u lokalnom koordinatnom sistemu, urađen je postupak uklapanja ovih koordinatnih sistema $\mathrm{u}$ jedan zajednički referentni koordinatni sistem složenog prostornog modela.

Na Slici 7 nalazi se skica realnog položaja 3D modela na terenu dobijena na osnovu snimljenih koordinata u UTM projekciji.

Prilikom uklapanja koordinatnih sistema 3D modela $\mathrm{u}$ zajednički koordinatni sistem super 3D modela, neopodno je definisati početnu tačku za svaki od modela i ugao rotacije.

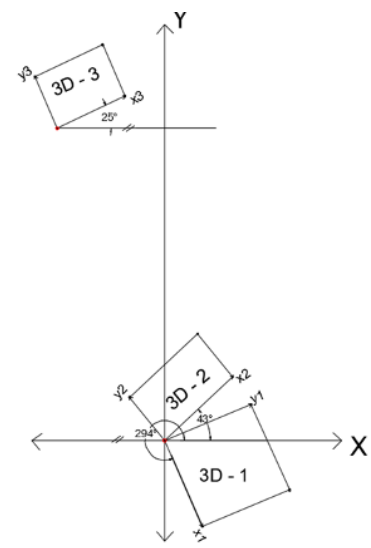

Slika 7 - skica 3D modela na terenu dobijena na osnovu UTM koordinata

Kao koordinatni početak svakog od njih uzete su tačke dobijene prilikom snimanja totalnom stanicom i unesen je ugao rotacije za svaki od modela. Ovakav način formiranja super 3D modela, rezultirao je georeferenciranim modelom u $R A D A N-\mathrm{u}$ u UTM projekciji (Slika 8).

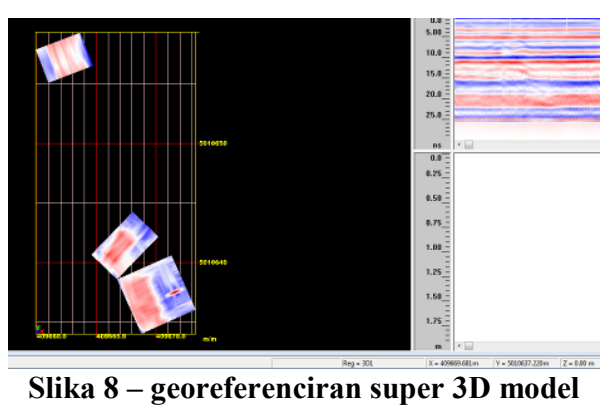

Na Slici 9 prikazani su rezultati super 3D modela dobijeni antenom frekvencije 400 (levo) i 900 (desno) MHz.

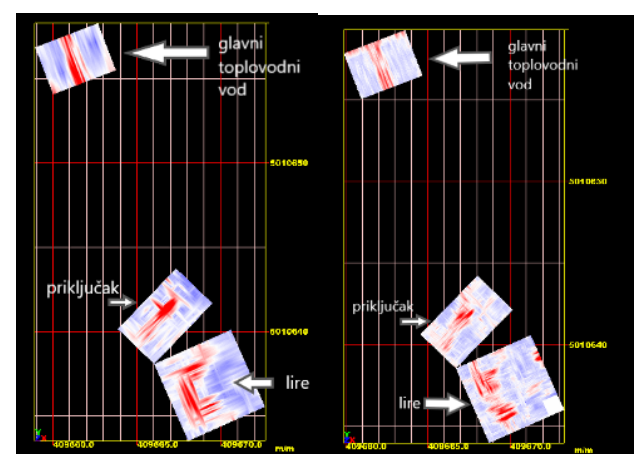

Slika 9 - uporedni prikaz super 3D modela dobijenih različitim antenama

\subsection{Iscrtavanje vodova}

$\mathrm{U}$ ovom radu primenjen je metod interaktivne interpretacije, koji se zasniva na odabiru pikova sa najvećom amplitudom, jer je pružao veću preciznost iscrtavanja. Slika 10 predstavlja uporedni prikaz iscrtanih cevi u modelima dobijenim antenama frekvencije 400 (levo) i 900 (desno) MHz.

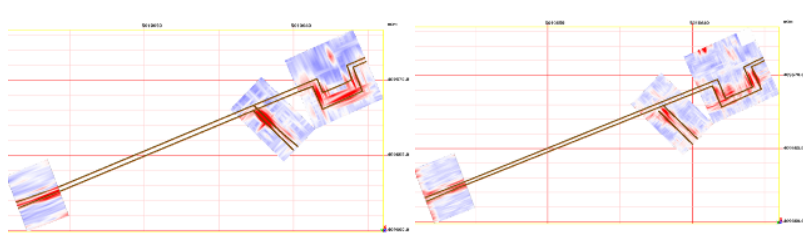

Slika 10 - uporedni prikaz iscrtanih vodova u modelima dobijenim antenama različite frekvencije

\subsection{Eksport 2D radargrama}

Format . ${ }^{*} k m l$ je glavni format aplikacije Google Earth koja omogućava virtuelni 3D prikaz Zemljine površi. Da bi eksport u ovaj format bio omogućen i dao tačan prikaz, radargrami, 3D ili Super 3D modeli moraju biti georeferencirani. Slika 11 prikazuje kako izgleda georeferenciran radargram u Google Earth-u.

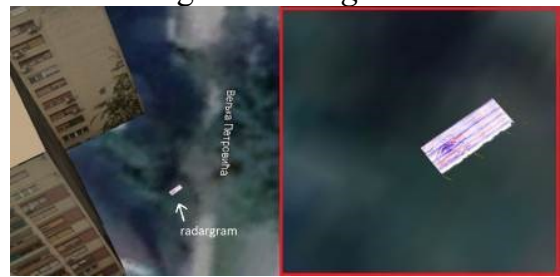

Slika 11 - georeferenciran radargram u Google Earth-u 


\subsection{Eksport 3D modela i super 3D modela}

U poglavlju 7.2.1, gde je reč o problemu georeferenciranja 3D modela, naglašeno je da tako georeferenciran model neće dati tačne rezultate, a samim tim ni njegov položaj u Google Earth-u neće biti istinit.

Međutim, ukoliko bi se takav model prilikom prikaza $\mathrm{u}$ $R A D A N$-u rotirao za odgovarajući ugao (Slika 7) i potom eksportovao, dobio bi se položaj modela na terenu koji odgovara stvarnom. Model sa oznakom 3D - 1 eksportovan je na objasnjen način i njegov prikaz $\mathrm{u}$ Google Earth-u vidi se na Slici 12. Ovaj način pruža samo vizuelno tačan položaj modela na terenu, ali problem georeferenciranja modela u $R A D A N-\mathrm{u}$ nije otklonjen.

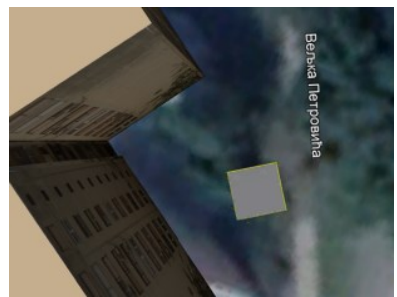

Slika 12 - prikaz 3D -1 modela u Google Earth-u

Formirani super 3D model model nema UTM koordinate $\mathrm{u}$ svojoj bazi, pa nije moguć njegov eksport $\mathrm{u} * . k m l$ format. Zato se georeferecniranju karakterističnih elemenata modela, pristupilo na drugačiji način.

Nakon eksporta iscrtanih vodova $\mathrm{u} * . d x f$ format $\mathrm{i}$ njihovim povezivanjem sa skicom snimljenih tačaka, dobijeni fajl otvoren je u $Q G I S$ alatu čijom upotrebom pomenuti fajl je izvezen $\mathrm{u} * . \mathrm{kml}$ format (Slika 13).

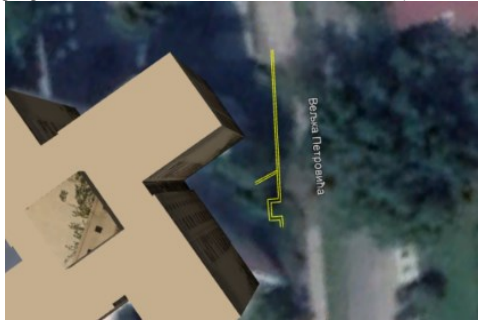

Slika 13 - prikaz georeferenciranog toplovoda

\section{DISKUSIJA}

U radu je uspešno detektovan toplovodni cevovod sa priključkom, na dubini od oko $0.60 \mathrm{~m}$ korišćenjem antena od $400 \mathrm{MHz}$ i $900 \mathrm{MHz}$. Slika 14 predstavlja uporedni prikaz radargrama dobijenih korišćenjem antene od 400 $\mathrm{MHz}$ (desno) i antene od $900 \mathrm{MHz}$ (levo).

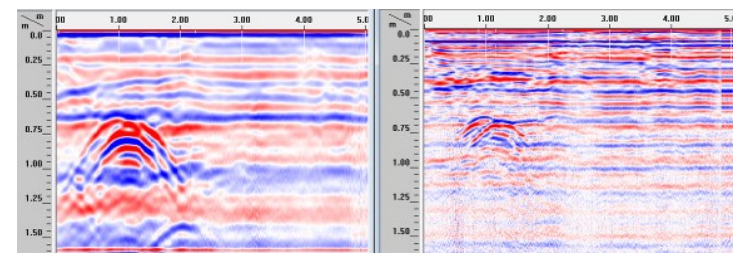

Slika 14: Uporedni prikaz radargrama dobijenih antenama različite frekvencije

Posmatrajući kontinualne refleksije vidljive u formiranim modelima, zaključuje se da su jasniji i kvalitetniji rezultati dobijeni snimanjem antenom od $400 \mathrm{MHz}$.

Preciznija mogućnost iscrtavanja vodova dobijena je u složenom modelu formiranom antenom od $900 \mathrm{MHz}$, iz razloga što je za formiranje tog modela razmak između dva susedna radargrama bio $0.5 \mathrm{~m}$, dok je pri korišćenju antene od $400 \mathrm{MHz}$ taj razmak iznosio $1 \mathrm{~m}$. Očekivano, veći broj radargrama u modelu daje veći broj hiperboličnih refleksija i samim tim bolju preciznost iscrtavanja.

Problem tačnog georeferenciranja 3D modela, postoji zbog korišćenja starije verzije $R A D A N$-a (6.6.2.7), odnosno nemogućnosti definisanja određenih parametara koji definišu pravilnu orijentaciju modela.

Nakon što je formiran super 3D model, otvoreni fajlovi pojedinačnih 3D modela izgledaju kao Slici 15.

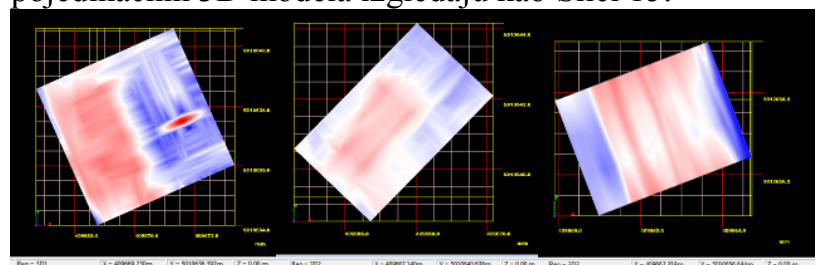

Slika 15 - pojedinačni 3D modeli

Sa pomenute slike se vidi da su ovim postupkom 3D modeli pravilno orjentisani i georeferencirani u $R A D A N$ u. Na ovaj način je, uprkos nedostatku programa kada je u pitanju formiranje ovih modela, rešen problem georeferenciranja 3D modela $\mathrm{u} R A D A N$-u.

\section{ZAKLJUČAK}

Dobijeni rezultati dokazuju da je moguće georeferenciranje podataka korišćenjem geodetskih instrumenata koji nisu direktno povezani sa georadarom, već su karakteristične tačke terena snimljene naknadno. Za dato rešenje georeferenciranja super 3D modela dovoljno je snimiti dve tačke modela, od kojih je jedna početna, a druga služi za određivanje rotacije modela. Ovakav način olakšava postupak skeniranja georadarom kada su neophodne koordinate područja.

Analizom 2D radargrama dobijenih upotrebom različitih antena, evidentno je da obe antene uspešno detektuju vodove od interesa, ali bi optimalno rešenje bilo korišćenje antene od $400 \mathrm{MHz}$ sa većim brojem radargrama $\mathrm{u}$ modelu.

Super 3D model omogućava povezivanje udaljenih delova vodova u jedan koordinatni sistem formirajući celinu. $\mathrm{Na}$ taj način olakšava se posao skeniranja, što je posebno značajno pri analiziranju većih područja.

\section{LITERATURA}

[1] Dr A. Ristić, Materijali sa predavanja i vežbi iz predmeta Detekcija objekata podzemne infrastrukture, 2016

[2] Geophysical Survey Systems, Inc. RADAN Manual

\section{Kratka biografija:}

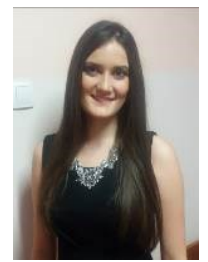

Miljana Marković rođena je u Sremskoj Mitrovici 1994. godine. Završila je gimnaziju opšteg smera u Šidu 2013. godine, nakon čega je upisala Fakultet Tehničkih Nauka, smer Geodezija i geomatika. Diplomski rad iz oblasti detekcije objekata podzemne infrastrukture odbranila je 2017. godine. 